\title{
Convenio colectivo aplicable y supuesto de reversión de servicios públicos ${ }^{1}$
}

\section{Applicable collective agreement and reversal supposition of public services}

\author{
Francisco Vila Tierno \\ Universidad de Málaga (España) \\ ORCID: http://orcid.org/0000-0001-5718-4160 \\ fvila@uma.es
}

\section{NOTA BIOGRÁFICA}

Francisco Vila Tierno es Profesor Titular de Derecho del Trabajo y de la Seguridad Social de la Universidad de Málaga, con una larga trayectoria como Magistrado (supl.) del TSJA, Administrador de la UNED en Málaga, Director del Título de Experto en Derecho del Trabajo en la UNIA, Codirector del Foro Social Aranzadi en Málaga e Investigador Principal en distintos Proyectos y contratos de investigación, entre ellos, el financiado por el INAP en el que se enmarca esta publicación. Su trayectoria profesional, académica e investigadora le han supuesto el reconocimiento de premios por su actividad, tramos de investigación y una participación continua y constante en Jornadas y Congresos en Universidades de prestigio, destacando su extensa relación con los centros de investigación italianos. Su labor se ha reflejado, además, en más de un centenar de publicaciones en editoriales y revistas de prestigio.

\author{
Miguel Ángel Gómez Salado \\ Universidad de Málaga (España) \\ ORCID: http://orcid.org/0000-0002-6003-7206 \\ magsalado@uma.es
}

\section{NOTA BIOGRÁFICA}

Miguel Ángel Gómez Salado es Investigador Contratado Posdoctoral (contrato puente financiado por el Plan Propio de Investigación y Transferencia) y Doctor en Ciencias Jurídicas y Sociales por la Universidad de Málaga. También es Máster en Asesoría Jurídica de Empresas, Máster en Profesorado (Premio Extraordinario de Máster) y Graduado en Gestión y Administración Pública (Premio Nacional de Fin de Carrera y Premio Extraordinario de Grado) por la Universidad de Málaga. Se encuentra vinculado al Departamento de Derecho del Trabajo y de la Seguridad Social de la Universidad de Málaga desde 2014 -mediante becas y contratos de investigación-, y está integrado en diversos proyectos y grupos de investigación -nacionales y autonómicos-.

\section{RESUMEN}

La negociación colectiva, como fuente de derecho constitucionalmente reconocida, determina el marco de las relaciones laborales en un ámbito fijado por los interlocutores, atendiendo a su capacidad y legitimación, e incluye, en su caso, un conjunto de obligaciones para las partes. El problema se presenta cuando la

1 Artículo publicado en el marco del Proyecto de Investigación financiado por el INAP Público y Privado en la gestión de los servicios públicos: reestructuración, externalización y reversión a la Administración. 
Administración recupera un servicio que con carácter previo ha sido externalizado y se plantean las dudas respecto al convenio que venía rigiendo para la empresa prestadora de tal servicio y sus trabajadores, en tanto que la Administración no ha sido parte negociadora del mismo. Problema que va desde la subrogación del personal a la propia especificación del conjunto de derechos y deberes laborales de tal personal. En el presente artículo se pretende dar las pautas para concretar el convenio colectivo aplicable en los citados supuestos de reversión a la luz de la actual normativa vigente y de la jurisprudencia más reciente.

\title{
PALABRAS CLAVE
}

Convenio colectivo aplicable; negociación colectiva; reversión de servicios públicos; subrogación convencional; contratos administrativos.

\begin{abstract}
Collective bargaining, as a constitutionally recognized source of law, determines the framework of labor relations in an area set by the interlocutors, based on their capacity and legitimacy, and includes, where appropriate, a set of obligations for the parties. The problem arises when the Administration recovers a service that previously has been outsourced and doubts arise regarding the agreement that had been ruling for the company that provides such service and its workers, while the Administration has not been a negotiating party of the company. A problem that goes from the subrogation of the personnel to the own specification of the group of rights and labor duties of such personnel. In this article, we intend to give the guidelines for specifying the collective agreement applicable in the aforementioned reversal cases in light of the current regulations and the most recent jurisprudence.
\end{abstract}

\section{KEYWORDS}

Applicable collective agreement; Collective bargaining; reversal of public services; contractual subrogation; administrative contracts.

\section{SUMARIO}

1. HIPÓTESIS DE PARTIDA. 2. EL MARCO DE LA NEGOCIACIÓN COLECTIVA EN LA ADMINISTRACIÓN PÚBLICA. SUJETOS NEGOCIADORES Y LEGITIMACIÓN NEGOCIAL COMO PUNTO DE PARTIDA PARA LA DETERMINACIÓN DE SU ÁMBITO SUBJETIVO. 3. LA SUBROGACIÓN CONVENCIONAL Y SUS CONSECUENCIAS. 4. LA SOLUCIÓN LEGAL Y JURISPRUDENCIAL. 4.1. LA NO INCLUSIÓN DE LAADMINISTRACIÓN EN EL ÁMBITO DE APLICACIÓN DE CONVENIOS EN LO QUE NO HA FORMADO PARTE EN EL PROCESO NEGOCIADOR. 4.2. LA SOLUCIÓN ALTERNATIVA: LA APLICACIÓN DEL CONVENIO COLECTIVO A LA ADMINISTRACIÓN PÚBLICA QUE NO PARTICIPÓ EN SU NEGOCIACIÓN POR IMPERATIVO DE LA LCSP. 4.3. LOS PROBLEMAS O SOLUCIONES ANTES DE LA STC 122/2018, DE 31 DE OCTUBRE DE 2018. 4.4. LA SOLUCIÓN A PARTIR DE LA STC 122/2018, DE 31 DE OCTUBRE DE 2018. 4.5. SÍNTESIS FINAL.

\section{HIPÓTESIS DE PARTIDA}

La Administración Pública ${ }^{2}$, como responsable de satisfacer las necesidades e intereses de los ciudadanos, puede asumir la gestión de los servicios de manera directa o de manera indirecta, esto es, externalizan-

\footnotetext{
2 Resulta determinante, a los efectos del personal, concretar el concepto de Administración Pública, puesto que su función o no como empleador puede influenciar de manera directa en el estatus del trabajador y que es objeto de este estudio. En este sentido, «el EBEP concreta su propio concepto de "Administraciones Públicas", considerando parte de éstas a la Administración General del Estado, (organizada conforme regulaba la Ley 6/1997, de 14 de abril, Ley de Organización y Funcionamiento de la Administración General del Estado, LOFAGE, y que ahora denomina "sector público" la Ley 40/2015, de 2 de octubre, de régimen jurídico del Sector Público, -que entrará en vigor el 1 de octubre de 2016-), las Administraciones Autonómicas, y de las Ciudades de Ceuta y Melilla, las Corporaciones Locales (provincial, municipal e Islas) y la Administración Institucional dependientes o vinculadas a cualquiera de las anteriores, (organismos autónomos, entidades públicas empresariales y Agencias). También entran en el concepto las Universidades públicas, y otros entes públicos como los Servicios de Salud, la Seguridad Social y sus Entidades Gestoras.

En contraposición quedan fuera del concepto de Administraciones Públicas en el EBEP, lo que se denomina el sector público empresarial, es decir, las fundaciones, empresas públicas o empresas privadas con participación mínima del sector público, cuyo personal tiene un vínculo jurídico privado, y están sometidos al Derecho del Trabajo, -sin perjuicio de que en algunas de ellas presten
} 
do los servicios de acuerdo a los procedimientos y vías contemplados en la Ley 9/2017, de 8 de noviembre, de Contratos del Sector Público, por la que se transponen al ordenamiento jurídico español las Directivas del Parlamento Europeo y del Consejo 2014/23/UE y 2014/24/UE, de 26 de febrero de 2014 (BOE núm. 272, de 9 de noviembre de 2017) -en adelante LCSP-.

En este sentido, según se preste el servicio de manera interna o externa, el marco normativo convencional aplicable será distinto, atendiendo al ámbito funcional del mismo. Siendo así, una de las cuestiones que puede ser analizada por la gestión de RR.HH. de la Administración en cuestión, es la conveniencia de ampliar o mantener plantillas bajo el paraguas de normas convencionales propias o, por el contrario, que sean los prestadores efectivos del servicio, en el caso de gestión indirecta, los que asuman la aplicación del convenio que corresponda.

En este orden, la valoración de la eficiencia y la eficacia como filtro para evaluar las ventajas para apostar por uno u otro modelo de gestión, no debe, en absoluto, basarse exclusivamente en términos económicos. Es más, la propia LCSP, en su art. 145.1.1. ${ }^{a}$ especifica los criterios sobre los que debe basarse la adjudicación del contrato, señalando la concurrencia de una pluralidad para la determinación de la mejor relación calidad-precio. Criterios de índole cuantitativo, pero también cualitativo, entre los que se encuentran los de carácter social -como la mejora de las condiciones laborales y salariales-.

En cualquier caso, la misma norma, con carácter previo, en su art. 122.2, al regular los «pliegos de cláusulas administrativas particulares», indica que en éstos «se incluirán los criterios de solvencia y adjudicación del contrato; las consideraciones sociales, laborales y ambientales que como criterios de solvencia, de adjudicación o como condiciones especiales de ejecución se establezcan... la obligación del adjudicatario de cumplir las condiciones salariales de los trabajadores conforme al Convenio Colectivo sectorial de aplicación».

De este modo, a través de aquel precepto en el marco de la norma que, recordemos, rige la contratación administrativa, se elude la aplicación de la prioridad aplicativa de los convenios colectivos de empresa prevista en el art. 84.2 del Estatuto de los Trabajadores -Real Decreto Legislativo 2/2015, de 23 de octubre, por el que se aprueba el texto refundido de la Ley del Estatuto de los Trabajadores (BOE núm. 255, de 24/10/2015), en adelante ET-, pero una vez que en el año 2017 se entienden superadas las situaciones en las que las Administraciones, sometidas a una situación de asfixia económica y con las limitaciones propias de las tasas de reposición, se veían abocadas a acudir a la contratación de empresas cuyo principal valor consistía en la reducción de los costes. Siendo así, se consigue invertir dicha regla estatutaria, en tanto que sitúa al convenio sectorial en una posición de preferencia frente al de ámbito empresarial y se evita que en el seno de la Administración presten servicios trabajadores -externos a la misma- por cuantías reducidas conforme a convenios colectivos propios aun desarrollando tareas equivalentes a la de los empleados públicos.

Sea como sea, lo relevante es que, si el servicio se asume de manera directa, pueden ser de aplicación los acuerdos o pactos colectivos que vinculen al personal funcionario y los convenios colectivos para el personal laboral y cuyo ámbito funcional sea la propia Administración que participa como interlocutora con legitimación durante su proceso de negociación. Pero si el servicio, como decíamos, se externaliza, los anteriores instrumentos colectivos dejarían de ser aplicables para tener cabida, en principio, el convenio colectivo del sector de actividad que incluya el servicio acordado -y antes, incluso, el convenio colectivo de empresa si ésta contaba con uno propio-.

Las condiciones laborales del personal, en tal caso, no son las mismas. Y es que los cambios respecto a la gestión pública o privada de los servicios públicos conllevan, al tiempo, un distinto estatus jurídico-laboral para los trabajadores que se destinan a tal fin, de manera que una decisión, en principio, de alcance administrativo o político, adquiere gran trascendencia desde el punto de vista de lo Social.

servicios funcionarios en calidad de funcionarios adscritos a una empresa pública, -como sucede en con la Sociedad Estatal de Correos y Telégrafos-. Por otra parte, existen órganos de la Administración (que no son en el concepto estricto "Administración Pública"), que tienen su propia regulación y a los que según previsión del propio EBEP en su artículo 4, solo se aplicará dicha norma cuando su propia legislación específica así lo establezca.

De forma similar se excluye del ámbito de aplicación del EBEP al personal al servicio de la administración independiente, u organismos reguladores, ahora denominados "autoridades administrativas independientes del ámbito estatal, Entidades de Derecho Público reguladas en los artículos 109 y 110 de la Ley 40/2015, de 1 de octubre, de Régimen Jurídico del Sector Público”, a los que será de aplicación en EBEP pero "en la forma prevista en sus leyes de creación" (Disposición Adicional Cuarta, del texto refundido del EBEP). Con esta fórmula se otorgando libertad a dichos organismos a la hora de elegir la norma de aplicación para sus empleados, que en la mayoría de los casos han optado por seguir como estaban originariamente, es decir, sometidos a la normativa laboral común.

En definitiva, la Administración Pública se configura como una organización productiva especial y compleja en distintos ámbitos, -tanto territoriales, como funcionales-, que se vinculan funcionarial y laboralmente con numerosos, y diversos tipos de empleados». AA.VV (MONEREO PÉREZ [dir.] y VILA TIERNO [coord.]), 2018. 
El problema, se plantea, en tales circunstancias, en una doble dirección: tanto si el servicio se prestaba en primer término de manera directa y después se externaliza, como a la inversa, esto es, en el caso de que exista una reversión del mismo. Y es que, tanto en uno como en otro caso, lo primero será determinar si existe una subrogación en las relaciones laborales y, en segundo término, concluir cuál será el convenio colectivo de aplicación. Cuestión que no resulta baladí, porque las condiciones labores reguladas en el ámbito de la empresa privada no tiene por qué coincidir con lo pactado en el seno de lo público.

En determinadas ocasiones, por tanto, lo que se produce es una simple huida del rol de empleador y de la aplicación directa del Derecho Laboral y, para ello, se acude a un proceso de externalización. Entre ellos se incluyen los supuestos de contratación y subcontratación que, en la esfera que nos ocupa, está condicionado por el respeto al interés público y a la reserva de actividades que deben ser desarrolladas por aquellos que tienen la condición de Funcionarios Públicos.

En este sentido, además de la LCSP, la norma de referencia es el art. 42 ET que debemos utilizar como contrapuesto a las cesiones irregulares del art. $43 \mathrm{ET}$. Aquel precepto, que regula fundamentalmente el régimen de responsabilidades -así como los derechos y deberes de las partes que intervienen en este negocio jurídico-implica la celebración de un acuerdo por el que una de ellas -comitente- externaliza una actividad que será desarrollada por una tercera -contratista-. De este modo, la Administración -empresario principalopta por ceder parte de los servicios o tareas que le son propios, para que sean ejecutados por una empresa que actúa como auxiliar. Pero al mismo tiempo, la contrata o subcontrata, en sentido estricto, no agota las posibilidades de colaboración en la prestación de servicios, puesto que dos entidades del sector público, una de carácter instrumental, pueden hacer uso de la denominada encomienda de gestión, en la que, el personal de esta última, presta servicios para la Administración titular de las competencias. Descrito de esta forma, es fácil situarse en el horizonte de una institución diferente, con una regulación completamente autónoma, como es la cesión ilegal de trabajadores del art. 43 ET. Y es que ésta disposición normativa es la que concreta cuando se incurre en la práctica irregular -salvo para las ETTs- de contratar a trabajadores para cederlos a terceros. Se interpone, por tanto, una figura entre empleador y empleado, con el único objeto, en la mayor parte de los casos, de simular que trabajadores que se encuentran completamente integrados en la estructura, funcionamiento y dinámica de la plantilla de la empresa, no forman parte de la misma, sino a una tercera que se presenta, formalmente, como el empresario contratante. Con todo ello se consigue -o se pretende conseguir-exonerarse de las responsabilidades laborales contraídas.

Es éste un fenómeno que no es ajeno a la Administración Pública, más bien al contrario, puesto que se repite de manera insistente en la misma, más aún por las limitaciones a la contratación laboral directa. Y en esta fórmula de colaboración entre lo público y lo privado participan, obviamente, unos prestadores de servicios. Aquí cobra especial importancia la distinción entre la realidad formal y material. Esto es, cuando se está realmente ante un fenómeno de subcontratación -o descentralización en general- o cuando lo que se produce es un fenómeno interpositorio, en el que no existe colaboración real, porque lo único que hay es una entidad que contrata, pero que no tiene ningún poder de organización y control sobre los trabajadores.

Es preciso, por tanto, comprobar los extremos de la contrata o externalización para diferenciarlo de la cesión ilegal, ya que, el efecto de ésta, va a ser que el trabajador elija en qué ámbito tiene la condición de indefinido y ello va a chocar con las limitaciones impuestas desde la Ley 3/2017, de 27 de junio, de Presupuestos Generales del Estado para el año 2017 (BOE núm. 153, de 28/06/2017) -LPGE 2017- en adelante, pero eliminadas, en parte, por la reciente sentencia del TC de 31 de octubre de 2018, sobre la que con posterioridad se volverá.

En ese sentido, resulta especialmente complejo, en ocasiones, delimitar si estamos ante un supuesto real de externalización -por ejemplo, con una encomienda de gestión-, puesto que únicamente si no lo es, estaremos ante una cesión ilegal, cuyo efecto, como es sabido, no podrá ser la continuidad como fijo en la Administración.

Por otra parte, no debe obviarse que nos situamos en la órbita de un proceso de contratación en el que tienen un enorme peso los trámites y requisitos de carácter administrativo. Pero que afectan de lleno a los aspectos laborales, ya que, la ausencia, por ejemplo, de determinados requisitos administrativos o del procedimiento adecuado (y su calificación jurídica subsiguiente en el orden contencioso-advo), nos puede llevar a encontrarnos con una figura como la del indefinido no fijo. Siendo así, para entender la externalización debemos remitirnos, necesariamente a los conceptos básicos en los supuestos de externalización en el sector público: contratas y subcontratas, concesión administrativa, concepto de propia actividad y encomienda de gestión que hoy por hoy se regulan en la recientemente aprobada en la LCSP. 
Teniendo en cuenta tal marco normativo, para contratar con la Administración, una empresa, de acuerdo a la LCSP -arts. 74 y ss-, debe acreditar su personalidad, su solvencia económica, financiera y técnica o profesional, además de la habilitación empresarial o profesional necesaria para desarrollar la actividad objeto del contrato, además de cumplir con los criterios sociales que la nueva Ley impone. Pero lo determinante es la efectiva existencia de una entidad empresarial, lo que puede ser determinante a efectos laborales (Vila Tierno, 2018).

Vayamos por partes.

\section{EL MARCO DE LA NEGOCIACIÓN COLECTIVA EN LA ADMINISTRACIÓN PÚBLICA. SUJETOS NEGOCIADORES Y LEGITIMACIÓN NEGOCIAL COMO PUNTO DE PARTIDA PARA LA DETERMINACIÓN DE SU ÁMBITO SUBJETIVO}

EI Título III ET regula la negociación colectiva que será de aplicación a empleadores y trabajadores por cuenta ajena. Y, entre ellos, a los que lo sean en el ámbito de lo Público. En un supuesto de externalización de servicios públicos, se propone la realización de éstos por un tercero, se está apostando por la gestión indirecta de aquellos servicios atendiendo a supuestas razones de eficiencia y eficacia, así como de optimización de los recursos y racionalización del gasto público (Vid. en profundidad: Castillo Blanco, 2017: 18 y ss).

De este modo, se plantea una "cesión» de la prestación del servicio público a través de las vías previstas para ello en la LCSP y ello supone que una entidad de naturaleza privada puede hacerse cargo de tal servicio, de manera que es su personal, el que está adscrito a las mismas en función de un contrato de naturaleza laboral, el que se reconoce como auténtico prestador de servicios, pero sin que éste adquiera la condición de empleado público a pesar del contexto en el que se desempeña su cometido.

Consecuencia de lo anterior encontramos un personal laboral cuyas condiciones de trabajo y empleo deben venir definidas, en principio, en la fuente de referencia en el Derecho del Trabajo: el convenio colectivo. Pero no olvidemos que aquel personal laboral, cuyo vínculo jurídico es con la entidad privada adjudicataria del servicio, estará, por tanto, en el ámbito de aplicación del convenio colectivo de empresa o de actividad por el que se rija la empleadora ${ }^{3}$.

La duda surge, por tanto, para los supuestos en los que, o bien la gestión de los servicios se asume de manera directa con personal que contrata la Administración en Régimen Laboral, o bien cuando se produce la reversión de los reiterados servicios públicos. Y ello, porque el convenio que había sido el marco regulatorio de las relaciones laborales durante la gestión directa o indirecta, no resulta de aplicación a la empresa que obtiene la concesión o a la Administración competente que revierte la concesión.

La reflexión anterior tiene una doble lectura. De un lado, es preciso comprobar si opera el mecanismo de subrogación convencional, pero en el caso de que el convenio colectivo que se aplicaba a la empleadora antes del cambio de titularidad así lo prevé y, de otro, definir la situación de los trabajadores respecto a la regulación convencional de sus condiciones laborales.

Dicho de otro modo, debemos recordar que el art. 3 ET especifica que entre las fuentes de la relación laboral se encuentra el convenio colectivo... ¿pero qué convenio colectivo? ¿cuál puede invocarse como fuente, $v$. gr., en un supuesto de reversión? Es preciso, por ello, dirigirnos al citado Título III ET para especificar los criterios conforme a los cuales se puede determinar cuál es la norma convencional de referencia (Vila Tierno, 2008).

A este respecto, el art. 82.2 y 3 ET especifica que «Mediante los convenios colectivos, y en su ámbito correspondiente, los trabajadores y empresarios regulan las condiciones de trabajo y de productividad... 3. Los convenios colectivos regulados por esta ley obligan a todos los empresarios y trabajadores incluidos dentro de su ámbito de aplicación y durante todo el tiempo de su vigencia».

A partir de tales enunciados, son dos las consecuencias más inmediatas. En primer lugar, que el precepto determina que unos trabajadores -a través de sus representantes- y empleadores específicos, en función al ámbito que le es propio, regulan las condiciones labores a través de la negociación colectiva. En segundo término, que el fruto de dicha negociación, vincula en exclusiva a los trabajadores y empresarios que estén en su ámbito. De esta forma, la primera consecuencia enlaza con los sujetos negociadores y los requisitos de legitimación negocial (Vid. en sentido amplio: Tomás Jiménez, 2013: 1-440; o Amaadachou Kaddur, 2015:

${ }^{3}$ En este sentido, las dudas se presentan exclusivamente sobre personal laboral, puesto que este el régimen de vinculación común que puede producirse entre trabajador y empleador, sea este último una entidad privada o pública, relación que no se desnaturaliza como consecuencia de un supuesto de externalización (SÁNCHEZ MORÓN, 2007: 85-86). 
267-304) en virtud de un principio de correspondencia representativa (García-Perrote Escartín y Mercader Uguina, 2014). Por su parte, la segunda de las afirmaciones concuerda con el hecho de que las partes negociadoras, en el marco de su libertad para fijar la unidad de negociación -pero sometida los requisitos de legitimación-, van a delimitar su ámbito subjetivo, sin que quepa, ni la inclusión de terceros, ni la exclusión de sujetos que pudieran incluirse en el mismo: «el artículo 83.1 del Estatuto de los Trabajadores, a tenor del cual "los convenios colectivos tendrán el ámbito de aplicación que las partes acuerden"» y en efecto tal precepto consagra el principio de libertad de las partes para definir la unidad de negociación. Pero, como ha señalado la doctrina del Tribunal Constitucional y la de esta Sala, esta regla no significa que las partes del convenio gocen de una libertad absoluta para determinar su ámbito de aplicación. Esa libertad está, en primer lugar, limitada por la necesidad de aplicar criterios objetivos en la delimitación del ámbito del convenio que se correspondan además con la legitimación de los negociadores (sentencias de 20 de septiembre de 1993 [RJ 1993, 6889], 23 de junio de 1994 [RJ 1994, 5470] y 21 de septiembre de 2006 [RJ 2006, 8730]), y por la propia configuración del convenio colectivo estatutario como norma del ordenamiento jurídico que tiene en principio una eficacia personal general, pues conforme al artículo 82.3 del Estatuto de los Trabajadores los convenios colectivos obligan a todos los trabajadores y empresarios incluidos en su ámbito de aplicación, lo que exige que la exclusión de lo que constituye el ámbito natural del convenio colectivo tenga una justificación objetiva y razonable (sentencia de 9 de octubre de 2003 [RJ 2003, 7732...). Esta exigencia de respetar el ámbito natural de la unidad de negociación se vincula en la doctrina constitucional con el principio de igualdad ante la Ley, en la medida en que el convenio colectivo como norma que se integra en el ordenamiento jurídico está vinculado por el artículo 14 de la Constitución (RCL 1978, 2836) y tiene, por tanto, que justificar los tratamientos diferentes que pueden producirse tanto en el establecimiento de condiciones de trabajo entre el personal incluido en su campo de aplicación (STC 27/2004 [RTC 2004, 27] y doctrina allí citada), como en lo que se refiere a las exclusiones que de su ámbito pueda establecer el propio convenio (SSTC 52/1987 [RTC 1987, 52] y 136/1987 [RTC 1987, 136]). En este sentido la STC 136/1987 señala que «la negociación colectiva de eficacia general está sujeta a muy diversos límites y requisitos legales, pues no en balde produce efectos entre "todos los empresarios y trabajadores incluidos dentro de su campo de aplicación", como prescribe el art. 82.3 del Estatuto de los Trabajadores y "esos límites alcanzan también a la determinación del ámbito de aplicación del convenio colectivo, aspecto éste que debe ser resuelto por las partes negociadoras respetando en todo caso los imperativos legales"» -STS de 14 marzo 2007 (RJ 2007/3389)-. Resolución judicial que invocamos para adelantar un problema posterior que es preciso ir acometiendo: la de la imposibilidad de excluir a colectivos de la aplicación de un convenio al margen de una justificación objetiva y razonable.

\section{LA SUBROGACIÓN CONVENCIONAL Y SUS CONSECUENCIAS}

Parece preciso hacer un inciso para destacar un elemento que no por obvio resulta menos relevante: no estamos ante un convenio colectivo que se regula en origen para determinar las condiciones laborales de un personal que va a prestar servicios para una Administración. En los supuestos de reversión, se trata de un personal que ya venía disfrutando de un marco normativo convencional cuando eran trabajadores de una entidad privada que tenía la condición de concesionaria de un servicio de gestión indirecta. O bien al revés, esto es, cuando el personal contratado por una entidad pública podría estar disfrutando de un convenio colectivo aplicable en tal marco y el servicio pasa a manos de la gestión privada, situación en la que dicho personal no estará incluido en el ámbito de regulación convencional aplicable para la empresa privada.

En esos supuestos en los que se produce un cambio en la titularidad empresarial pueden -o no- reconocerse supuestos de subrogación empresarial, bien sea porque se cumplen los parámetros del art. $44 \mathrm{ET}^{4}$, bien porque se trate de un caso de subrogación convencional, o bien, por último, porque sea consecuencia de otra disposición de naturaleza diversa.

Dejando al margen otras opciones, nos interesa, en este análisis, centrarnos en la de carácter convencional, en tanto que si se dan los elementos del citado art. 44 ET se seguirá el procedimiento expresamente previsto en el mismo, mientras que si entendemos que existe subrogación convencional ¿cuál sería el convenio aplicable?

4 Con todos los extremos y matices que ello implica y con las interpretaciones tanto de la jurisprudencia comunitaria y nacional con supuestos como los de sucesión de plantillas. Vid. SSTS 7 de mayo de 2016 (RJ 2016/1702) ó 1 de junio de 2016 (RJ 2016/3745) 
En este sentido, es bastante frecuente que la negociación colectiva, como mecanismo garantista en favor de los trabajadores, establezca fórmulas para el mantenimiento del empleo para los supuestos en los que no alcancen las previsiones del tan reiterado art. $44 \mathrm{ET}$, especialmente en aquellos sectores en los que práctica ha manifestado su necesidad 5 . En este contexto, se ha podido establecer la obligación convencional de continuidad de los trabajadores cuando hay cambios que afectan al titular de la explotación o gestor de los servicios, así como el mantenimiento, si cabe, de determinadas condiciones laborales.

A tal efecto, de un modo reiterado los órganos judiciales de lo Social han venido indicando que no pueden actuar como presupuestos de la subrogación legal ni la contrata ni la concesión administrativa, en tanto que no pueden reconocerse como unidades productivas autónomas -indicando, no obstante, las salvedades cuando la infraestructura u organización empresarial precisa se pone a disposición del concesionario o contratista; vid. v. gr. SSTS 23 de mayo de 2005 (RJ 2005/97], 21 de septiembre de 2012 (RJ 2013/2388) y 24 de julio de 2013 (RJ 2013/6797)-. En tal caso, y excepto en los sectores en los que la sucesión de plantilla de carácter voluntario se produce por tratarse de actividades en las que la actividad gira en torno a la mano de obra esencialmente, la subrogación operará si el convenio colectivo así lo establece -STS 7 de junio de 2016 (RJ 2016/2933)-. En estas situaciones:

a) las empresas obligadas son aquellas que se encuentran vinculadas por el convenio colectivo del que forman parte en su ámbito funcional, ya que, como se ha insistido, dicha obligación no alcanza a la empresa adjudicataria si no está en el marco de tal convenio -STS de 17 de junio de 2011 (RJ 2011, $5423)-$

b) No se pueden establecer cláusulas obligacionales para quienes no han sido interlocutores en el proceso de negociación, ni condiciones de trabajo, como contenido normativo, a aquellas empresas fuera del ámbito del convenio -STS de 10 de diciembre de 2008 (RJ 2008/7678)-

Y, por otra parte, ni el fenómeno subrogatorio se produce de manera automática, ni los efectos están tasados, sino que dependerán de los términos del acuerdo fruto de la actividad negociadora ${ }^{6}$. De tal forma que, únicamente, en el caso en el que no se estableciera una regulación específica, se aplicaría, pero de manera supletoria, la ordenación estatutaria, por lo que, a falta de acuerdo expreso el convenio colectivo aplicable seguiría siendo el que venían disfrutando con anterioridad los trabajadores subrogados, hasta la fecha de su fecha de vencimiento o hasta la entrada en vigor de un nuevo convenio colectivo nuevo que les resulte de aplicación -STS 31 de mayo de 2017 (RJ 2017/3163)-.

No obstante, la STS 3545/2018, de 27 de septiembre, viene a formular lo siguiente: «Primera.- Hay transmisión de empresa encuadrable en el art. 44 ET si la sucesión de contratas va acompañada de la transmisión de una entidad económica entre las empresas saliente y entrante.

Segunda.- En actividades donde la mano de obra constituye un factor esencial, la asunción de una parte relevante del personal adscrito a la contrata (en términos cuantitativos o cualitativos) activa la aplicación del artículo $44 \mathrm{ET}$.

Tercero.- Cuando (como en el caso) lo relevante es la mano de obra (no la infraestructura) la subrogación solo procede si se da esa asunción de una parte relevante (cuantitativa o cualitativamente) del personal.

Cuarto.- El hecho de que la asunción de una parte relevante de la plantilla derive de lo preceptuado por el convenio colectivo no impide la aplicación de la anterior doctrina».

Dicho de otro modo, la resolución judicial, que implica un cambio radical en el criterio del TS, viene a establecer que cuando opera la sucesión por la asunción de la mayor parte de la plantilla, resulta irrelevante que se plantee en el marco del convenio colectivo como subrogación convencional, puesto que tendrá todos los efectos y caracteres de una subrogación legal subsumible en ámbito de la Directiva comunitaria.

Parece que, a partir de tales conclusiones, cuando la gestión se cede a un tercero y no se reconoce el fenómeno del art. $44 \mathrm{ET}$, la obligación convencional de subrogación o el mantenimiento del convenio colectivo que pudiera aplicarse en la Administración no alcanza a la empresa por no ser esta parte del ámbito de aplicación de aquél. Pero únicamente en el caso de que no sea aplicable el supuesto previsto en la referida STS de 27 de septiembre de 2018. Ello nos obliga centrarnos en la reversión y sus diferentes problemas e interpretaciones. Interpretaciones que, a priori, no se apartan mucho de lo ya planteado.

5 En este sentido, lo habitual es que el convenio colectivo de ámbito sectorial regule este tipo de cláusulas, pero ello no excluye que un convenio colectivo empresarial pudiera contener compromisos de asumir plantillas en supuestos de esta naturaleza.

6 Como los relativos a la antigüedad del trabajador, al procedimiento de transmisión o a la responsabilidad asumida. 


\section{LA SOLUCIÓN LEGAL Y JURISPRUDENCIAL}

\subsection{La no inclusión de la Administración en el ámbito de aplicación de convenios en lo que no ha formado parte en el proceso negociador}

La normativa actual que regula los supuestos de reversión no ayuda, precisamente, a una fácil interpretación de este complejo y enmarañado asunto que es muy simple en cuanto a su lógica de fondo: ¿cuál es el convenio colectivo aplicable al personal en supuestos de reversión.

No obstante, antes de una regulación específica para los supuestos de reversión y la subrogación empresarial, los órganos judiciales del Orden Social se venían pronunciando sobre una cuestión que parece determinante en este punto y que tiene que ver con la aplicación -o no- de la Administración de un convenio colectivo del que no ha formado parte, entendiendo, de manera reiterada que no cabía incluir a la misma en el ámbito de un convenio del que no había sido parte -SSTS de 17 de junio de 2011 (RJ 2011/5423), de 11 de julio de 2011 (RJ 2011।5667), de 26 de julio de 2012 (RJ 2012l9976), de 21 de abril de 2015 (RJ 2015।2177), de 19 de mayo de 2015 (RJI2015/2886) y de 27 de febrero de 2018 RJ 201811144)-.

Interpretación que casaba con el texto de la anterior LCSP que, en su art. 301, excluía expresamente la consolidación de las personas que hayan realizado los trabajos objeto del contrato como personal del ente, organismo o entidad del sector público contratante -STS 21 de abril de 2015 (RJ 2015, 2177)-. Pero, en este sentido, recordemos que la doctrina ha reconocido tanto la aplicabilidad del art. $44 \mathrm{ET}$, como los problemas que se pueden deducir, respecto al personal laboral los supuestos de reversión de servicios públicos. Y así, como afirma nuestra mejor doctrina «el imperativo legal y la coherencia con la Directiva 2001/23/CE y el art. 44 del ET (y atendiendo al art. 7 del EBEP), obliga a aplicar el régimen jurídico laboral de garantías generales previstas en ese grupo normativo regulador que integra el Derecho social comunitario y el Derecho nacional» (Monereo Pérez, 2016: 307).

Y es que la subrogación empresarial sería predicable en el marco de la Administración Pública sin que pueda invocarse la normativa interna para evitar tal aplicación, dada la prevalencia del Derecho Comunitario y así, v. gr. «La afirmación del art. 301 TRLCSP no puede, ni impedir la aplicación del art. 44 del ET, que deviene imperativa en atención a las normas comunitarias cuya interpretación siempre ha considerado que la Administración Pública no queda eximida de las obligaciones en materia de sucesión de empresas (STCE 26/09/2000, C-175/99, asunto Mayer; STUE 29/07/2010, C-151/09, asunto UGT/FSP), ni tampoco debe entenderse como una prohibición absoluta de que la Administración asuma el personal con ciertos condicionamientos» (Alfonso Mellado, 2016: 37).

No obstante lo anterior, la doctrina científica, de manera mayoritaria, y al amparo de esta línea jurisprudencial antes citada, niega la aplicabilidad de los convenios sectoriales a la Administración (Cruz Villalón, J. 2016, pág. 42; Gómez Álvarez, T. 2004: pág. 282; López Cumbre, L. 2017, pág. 126 y ss.; Sala Franco, T. 2018: pág. 204; Gorelli Hernández, J, 2018). El argumento jurisprudencial del que se hace eco la doctrina se apoya en que «el convenio colectivo no puede (...) en su contenido normativo, establecer condiciones de trabajo que hubieran de asumir empresas que no estuvieran incluidas en su ámbito de aplicación. Así lo deja precisado el invocado art. 82.3 del citado Estatuto de los Trabajadores al disponer que los convenios colectivos regulados por su Título III obligan a todos los empresarios y trabajadores incluidos en su ámbito de aplicación en el que solo pueden estar comprendidos quienes, formal o institucionalmente, estuvieron representados por las partes intervinientes en la negociación del convenio»-la ya citada STS de 17 de junio de 2011 aludiendo a pronunciamientos anteriores-. Al tiempo que se añade que «el convenio colectivo no puede contener cláusulas obligacionales que afecten a quienes no son parte en la negociación, ni en su contenido normativo cabe establecer condiciones de trabajo que hubieran de asumir empresas que no estuvieran incluidas en su ámbito de aplicación» -STS de 21 de abril de 2015 (cit)-.

Siguiendo tal interpretación, se ha entendido que una entidad, pública o privada, por el simple hecho de asumir de manera directa la ejecución de unos servicios no puede considerarse una empresa del sector de actividad y, en consecuencia, no estaría sujeta a las prescripciones normativas u obligacionales del convenio colectivo de referencia en el mismo.

\subsection{La solución alternativa: la aplicación del convenio colectivo a la Administración Pública que no participó en su negociación por imperativo de la LCSP}

Sin embargo, diferentes son los matices que deben destacarse para conseguir una interpretación completa. De un lado, que los pronunciamientos judiciales son anteriores a la regulación en los términos actuales 
de la LCSP y, de otro, que si estamos ante la posibilidad de una subrogación convencional debemos estar a los términos exactos de la misma.

En ese sentido, si el convenio colectivo obliga en los supuestos de sucesión de contratas, una hipótesis de reversión no puede identificarse propiamente con la existencia de una contrata. De este modo, puede que lo que se analice no son los efectos o el alcance de la subrogación convencional de manera genérica, sino un caso concreto de una regulación de la norma convencional en unos términos específicos en los que no tenga cabida una reversión, sino la sucesión de contratas ${ }^{7}$. No puede interpretarse, por tanto, que no es aceptable en ningún caso la subrogación convencional en una Administración, cuando el convenio aplicable a la empresa que venía prestando el servicio con carácter previo a la reversión así lo disponía, aunque esto no deja de ser una opinión que contrasta con la doctrina dominante, tal y como se ha adelantado.

Y es que la mayor parte de la doctrina invoca la primera de las razones señaladas en el subapartado anterior, a la que le da un peso decisivo, entendiendo que no se puede aplicar el convenio de un sector a la Administración que no ha sido parte en el proceso de negociación.

Pero ello puede chocar con varios elementos que pueden ser significativos.

En primer lugar, puede dar lugar a un efecto no deseado, como podía ser la extinción de las relaciones laborales que se han ido manteniendo en los sucesivos cambios de contratas. Efecto no deseado salvo que la Administración persiga tal consecuencia. Una consecuencia que, en cualquier caso, habría que interpretar de conformidad con la Disp. Adic. 26. ${ }^{\circ}$ LPGE 2017, de acuerdo a su modificación operada en 2018 -Ley 6/2018, de 3 de julio, de Presupuestos Generales del Estado para el año 2018 (BOE núm. 161, de 4 de julio de 2018)-.

En segundo lugar, que plantearía dudas respecto a la aplicabilidad del art. 130.3 LCSP que parece taxativo en lo que respecta al mantenimiento del empleo y de las condiciones laborales.

En tercer lugar, que existirían serias dudas sobre el marco convencional regulatorio de las condiciones laborales del personal subrogado.

Pero existe, además, otro problema de interpretación, de especial relevancia, que puede, no obstante, situar este debate en un segundo plano y que ya hemos sugerido anteriormente con la mención a la STS de 27 de septiembre de 2018. Se trata de una cuestión planteada en la STSJ de Galicia de 26 de julio de 2018 (CENDOJ 15030340012018102349) y en la que aparece como supuesto de hecho una subrogación convencional entre contratas que se suceden en la gestión de un servicio para una el Museo de las peregrinaciones de Santiago de Compostela, dependiente de la Consellería de Cultura de la Xunta de Galicia.

Las circunstancias que se analizan se refieren, en este caso, a una posible responsabilidad solidaria como consecuencia o no de la existencia de una subrogación legal y no únicamente la de naturaleza convencional, pues en ésta última hipótesis serían predicables los efectos previstos expresamente en la misma. Y las dudas surgen, primero, por incluirse en el convenio colectivo de aplicación una subrogación convencional con efectos limitados expresamente.

Pero la Sala, apoyándose en la STS de 7 de abril 2016 (rec. 2269/2014) -interpretando precisamente la misma norma convencional- recuerda que «en los supuestos de sucesión de contratistas la subrogación no opera en virtud del mandato estatutario -artículo 44 ET- si no se ha producido una transmisión de activos patrimoniales o una "sucesión de plantillas", en aquellos sectores en los que la actividad descansa fundamentalmente en la mano de obra -STS de 27 de octubre de 2004, rec. 899/02, que recoge la doctrina comunitaria-. La subrogación se produce en virtud del mandato contenido en el convenio colectivo aplicable. Por tanto, la asunción de los trabajadores de la empresa anterior no responde al supuesto de sucesión en la plantilla derivado del hecho de que la nueva contratista se haga cargo voluntariamente de la mayoría de los trabajadores que prestaban servicios en la contrata. Al contrario, en estos casos la sucesión de la plantilla es el resultado del cumplimiento de las disposiciones establecidas en el convenio aplicable». Debemos, por tanto, centrarnos en un matiz, y es que se dice, literalmente, «si no se ha producido» un supuesto de sucesión de plantillas. De esta forma, este hecho es el determinante, puesto que si hay «una transmisión de una entidad económica, en tanto conjunto de trabajadores que ejerce de forma duradera una actividad común desmaterializada, a cuya transmisión de la actividad se une la asunción de la plantilla, lo que nos situaría en el ámbito del art. 1 de la Directiva 2001/23/CE, conforme a la doctrina comunitaria (STJUE Süzen; Hernández Vidal y otros, Hidalgo y otros, C-173/96, o Temco, C-51/00 ), y debería serle de aplicación el art. 3.1 de

7 En la sentencia citada en primer término se aludía expresamente a un precepto convencional que literalmente se refería una subrogación que «operará en todos los supuestos de sustitución de contratas...» (art. 52 Convenio General del Sector de Limpieza Pública Viaria). 
la misma. Y nos resultaba ciertamente dudoso que pudiera eludirse su aplicación solo porque la decisión no fuera fruto de la autonomía individual de la cesionaria sino consecuencia de una obligación impuesta por la autonomía colectiva».

Así, y en respuesta a cuestión prejudicial de Derecho comunitario planteada, el TJUE en sentencia de 11-7-2018- C-60/17 dispone «que el artículo 1, apartado 1, de la Directiva 2001/23 debe interpretarse en el sentido de que esta Directiva se aplica a una situación en la que un arrendatario de servicios ha resuelto el contrato de prestación de servicios de vigilancia de instalaciones celebrado con una empresa y, a efectos de la ejecución de esta prestación, ha celebrado un nuevo contrato con otra empresa que se hace cargo, en virtud de un convenio colectivo, de una parte esencial, en términos de número y de competencias, del personal que la primera empresa destinaba a la ejecución de dicha prestación, siempre y cuando la operación vaya acompañada de la transmisión de una entidad económica entre las dos empresas afectadas». O dicho de otro modo «el TJUE entiende que en este caso ha existido una transmisión de una entidad económica y que el hecho de que la sucesión de plantilla venga impuesta por el convenio colectivo "no afecta, en cualquier caso, al hecho de que la transmisión se refiere a una entidad económica" (con cita de la sentencia SeguritasC.200/16, posterior al planteamiento de nuestra cuestión), por lo que sería incardinable en el ámbito del art.1 de la Directiva» $-\mathrm{FJ} 4 .^{\circ}-$.

Lo que debe entenderse que, en el marco de la norma de transposición, el art. $44 \mathrm{ET}$, dispone que el nuevo empleador queda subrogado en los derechos y obligaciones laborales existentes, con la especial referencia al régimen de los convenios colectivos.

Por tanto, en estos supuestos, lo relevante, no sería que el convenio colectivo establezca un mecanismo subrogatorio, sino que se produzca o no un supuesto de sucesión de plantillas porque, en tal caso, y como consecuencia del principio de jerarquía normativa prevalecería la norma de rango superior. Esta doctrina, que se formula de manera primigenia en esos términos, es objeto de ratificación en todos sus extremos por la determinante y reiterada STS de 27 de septiembre de 2018.

Ello obligaría a la aplicabilidad automática del convenio preexistente, pero, no obstante, debe recordarse que, en las transmisiones señaladas, se requiere el elemento de la voluntariedad respecto a la aceptación de la plantilla, lo que chocaría con una posible reversión. De un lado, porque en virtud de lo establecido en la LPGE 2017 no se podía integrar con la condición de empleados públicos aquellos trabajadores que provienían, entre otras, de una reversión (lo que no quiere decir que no pueda existir subrogación), pero fundamentalmente por las dificultades que tendría o podría tener para manifestar su voluntad en este sentido y, sobre todo, por el mismo argumento anteriormente citado: la Administración no ha sido parte en el proceso negociador, por lo que no ha manifestado su voluntad en el marco de esa norma colectiva.

En este contexto, ahora sí, debemos centrarnos en la solución legal que opera actualmente, y para ello, debemos recordar que el art. 130.3 LCSP dispone que «En caso de que una Administración Pública decida prestar directamente un servicio que hasta la fecha venía siendo prestado por un operador económico, vendrá obligada a la subrogación del personal que lo prestaba si así lo establece una norma legal, un convenio colectivo o un acuerdo de negociación colectiva de eficacia general».

Ello ha sido interpretado por la mayor parte de la doctrina (Vid. v. gr. por todos Gorelli Hernández, 2018) como que «aparentemente» se admite la subrogación convencional sin ambages, al establecer esa obligación para la Administración si así se reconoce en un convenio colectivo o acuerdo de eficacia general. Sin que la norma, novedosa, incluya matiz alguno. Pero, siguiendo la misma doctrina invocada anteriormente, se vuelve a defender que ello no es aplicable respecto a las Administraciones que no han formado parte de los procesos negociadores que han incluido tal compromiso.

No podemos, sin embargo, compartir tal afirmación y ello por varios motivos, en primer lugar, por lo que entendemos que significa la inclusión de tal precepto en cuanto a la finalidad de la norma. Y esta puede ser interpretada de acuerdo a tres fines: el mantenimiento del empleo, la continuidad del marco regulador y, puede que especialmente, la idea de incluir cargas y complejidad para frenar los supuestos de reversión de los servicios públicos.

Repasemos cronológicamente los últimos cambios normativos -antes del último pronunciamiento al respecto del TC- que pueden tener influencia en una respuesta al problema que planteamos, señalando la fecha de entrada en vigor de cada una de ellas:

$$
\text { Primera.- DA } 26 \text { LPGE } 2017 \text { (5/7/2018): }
$$

«Uno. Con efectos desde la entrada en vigor de esta Ley y vigencia indefinida, las Administraciones Públicas del artículo 2 del texto refundido de la Ley del Estatuto Básico del Empleado 
Público, aprobado por el Real Decreto Legislativo 5/2015, de 30 de octubre, no podrán considerar como empleados públicos de su artículo 8 , ni podrán incorporar en dicha condición en una Administración Pública o en una entidad de derecho público:

a) A los trabajadores de los contratistas de concesiones de obras o de servicios públicos o de cualquier otro contrato adjudicado por las Administraciones Públicas previstas en el artículo 2.3 de la Ley 40/2015, de 1 de octubre, de Régimen Jurídico del Sector Público, cuando los contratos se extingan por su cumplimiento, por resolución, incluido el rescate, o si se adopta el secuestro o intervención del servicio conforme a la legislación de contratos del sector público que resultase aplicable a los mismos...

... Al personal referido en los apartados anteriores le serán de aplicación las previsiones sobre sucesión de empresas contenidas en la normativa laboral».

Segunda.- Art. 130.3 LCSP (9/11/2017) -cinco meses más tarde-.

Tercera.- DF 42 LPGE 2018 (29/6/2018):

«Uno. Se suprime el último párrafo de la disposición adicional vigésima sexta. Uno de la Ley 3/2017, de Presupuestos Generales del Estado para el año 2017».

Es decir, que se suprime el párrafo que hemos remarcado en la primera de las normas citadas.

La explicación puede estar relacionada con una más adecuada coordinación entre las normas en juego, en tanto que mientras que la DA 26. ${ }^{a}$ LPGE remitía a un único supuesto o vía de subrogación, el establecido en la normativa laboral, la LCSP que se publica 5 meses más tarde, dispone diferentes escenarios subrogatorios, de tal forma que, la sucesión empresarial contemplada en esa última norma no podría considerarse, propiamente, «normativa laboral». Dicho de otro modo, la LCSP establece una obligación para la Administración que se separa de la regulación legal de este supuesto para el ámbito privado, aunque, para su perfeccionamiento, y al tratarse de una institución puramente laboral, siga los cauces que dicha normativa y su interpretación judicial han seguido al respecto. Por este motivo, la DF 42. ${ }^{a}$ LPGE elimina lo que puede entenderse como una restricción del modelo subrogatorio en el marco de lo público para dar cabida a la previsión de la LCSP. Y esta previsión, queremos entenderla como absoluta, clara y novedosa, introduciendo esa obligación de manera expresa para las entidades públicas que deciden revertir el servicio.

Cierto es que la Administración, en esos supuestos, no ha tenido porqué mostrar su conformidad para asumir la obligación convencional para subrogarse, pero no es menos cierto que si existe una regla fija y explícita mediante lo establecido en el art. 130.3 LCSP, la Administración si manifestaría su intención de subrogarse, al asumir, sin que exista obligación para ello, la decisión de revisión. Dicho de otro modo: la decisión de reversión lleva aparejada la carga de subrogarse cuando la norma convencional previa de aplicación en el supuesto de externalización así lo incluye. Porque así lo dispone la norma legal, una norma cuyo espíritu es la remisión continua al convenio colectivo de sector (por lo que resultaría incongruente ahora huir del mismo), porque la Administración conoce las repercusiones con carácter previo y porque no se trata del único supuesto en el que se aplica una norma convencional a quién no ha participado en su elaboración.

Así, por ejemplo, el art. 44 ET así lo dispone -sobre lo que volveremos más adelante- o incluso hay interpretaciones judiciales que así lo admiten, es decir, que asumen la aplicabilidad de la cláusula subrogatoria incluida en un convenio colectivo supraempresarial a empresas ajenas a su ámbito funcional, bien en casos extraordinarios (STS de 21 de abril de 2015), bien atendiendo a un criterio funcional (STS de 10 de febrero de 2014 [RJ 2014/ 1622] o STSJ del País Vasco de 15 de septiembre de 2015 referida a sucesión de concesiones administrativas), o finalmente con interpretaciones con matices, como en la STS de 27 de febrero de 2018 (RJ 2018/1044), que aunque parte de la exclusión de aplicación de un convenio porque la Administración no ha sido parte, cuestiona esta última afirmación al entender que el servicio se prestaba por empresas municipales que no podían excluirse de «aquella parte».

\subsection{Los problemas o soluciones antes de la STC 122/2018, de 31 de octubre de 2018}

A pesar de todo ello, la entrada en vigor de la LCSP lo hace sin que se altere la regla básica y con carácter indefinido que se instaura en 2017 (LPGE): la prohibición de considerar empleados públicos ni integrarlos en esa condición a los trabajadores subrogados (Monereo Pérez, 2016; Vila Tierno, 2018). Regla que, por 
cierto, es la madre de todas las dudas: si no son trabajadores públicos ¿qué son y que estatus tienen? Y, en consecuencia ¿cuáles son sus condiciones laborales?

Con algo más de detalle podemos ampliar la afirmación anterior, esto es, por la que se excluye la posibilidad de incorporar como empleados públicos a los trabajadores que prestaran servicios para un tercero en el marco de una externalización que finaliza o existe reversión -salvo sentencia judicial o desarrollo de proceso de acceso de acuerdo a principios constitucionales-, aunque se preconiza que le es de aplicación, a todos los efectos, las previsiones sobre sucesión de empresas en la normativa laboral (Vila Tierno, 2018). De este modo, nuevamente aparecen como marco de referencia tanto el art. $44 \mathrm{ET}$, como las disposiciones en esta materia de la LCSP, así como lo regulado como sucesión convencional en el seno de la negociación colectiva.

Lo curioso de todo ello es que se afirma que puede operar un supuesto de subrogación laboral en la administración pública sin que los afectados por el mismo tengan la condición de empleados públicos. No obstante, ya reconocimos con anterioridad que operan los efectos de la subrogación en el marco de la Administración Pública y según predica el EBEP, la prestación que se daría sería como empleado público (vid. arts. 8 a 11), ¿qué consecuencias tendrá la limitación de la LPGE? Ciertamente, a pesar del espíritu omnicomprensivo que parece desprenderse del legislador presupuestario, no le faculta a ignorar el cumplimiento de la normativa comunitaria e interna aplicable, más aún cuando en la misma norma presupuestaria se alude a la aplicación del ordenamiento laboral (Molina Navarrete, 2017: págs. 94 y 95).

A partir de ello, la doctrina administrativista ha reconocido una nueva ampliación de las excepciones a las relaciones ordinarias recogidas en el EBEP, hasta el punto que se vienen a distinguir las siguientes relaciones de prestación de servicios laborales en el contexto de lo público: «el personal directivo sujeto a la relación laboral especial de alta dirección; el personal laboral, fijo o temporal, sujeto al EBEP; el personal laboral de sociedades públicas y fundaciones -a las que el EBEP y el resto de normativa de derecho público solo les será de aplicación en la medida en que, de forma expresa, estas normas se refieran a ellos-; el personal laboral indefinido no fijo en los supuestos que proceda dicha calificación; y, por último y por ahora, en el caso de la subrogación en las relaciones laborales, estos trabajadores, carentes de la condición de empleados públicos y sujetos a su propio régimen jurídico pero que, no se olvide, prestan servicios en el sector público y perciben sus retribuciones del mismo» (Castillo Blanco, 2017: pág. 124). Se trata, por tanto, del colectivo de «trabajadores subrogados» que se plantea como un problema de categorización jurídica, pero que no va a suponer, en ningún caso, la inaplicación de la normativa en materia de subrogación. De este modo, parece evidente que la propia Administración sí debería, al contrario que en el supuesto de contratación o acceso irregular, reconocer los efectos de la subrogación y, en consecuencia, el vínculo laboral de trabajador y ente público, pero no su condición de empleado público, puesto que tal reconocimiento se reduce a los supuestos excepcionales previsto en la Ley: sentencia judicial o proceso regular en determinados ámbitos.

En definitiva, el legislador, siguiendo la confusa jurisprudencia del Orden Contencioso-administrativo -STS de 16 de febrero de 2016 (Sala Tercera), rec. 3944/2014- reconoce al personal como laboral de la administración, pero sin ser empleado público. Pero, de un modo, si cabe, más complejo: los órganos judiciales de lo Social, reconocen, en estos casos, a los trabajadores subrogados como trabajadores indefinidos no fijos, pero si recordamos, el art. 8 EBEP reconoce esta condición únicamente a empleados públicos, categoría que hoy les niega el legislador presupuestario (Molina Navarrete, 2017: pág. 97).

Sea como sea, lo interesante de lo anterior, es el hecho de que acceden a la Administración, para la que prestan servicios. Cuestión distinta es la naturaleza de su relación con aquella al no reconocérsele como empleados públicos. Y lo relevante es si por esta «anomalía» quedarían o no sujetos al convenio colectivo aplicable a los empleados de la Administración. De un lado, debe tenerse presente que éstos no fueron representados en el proceso de negociación, sencillamente, porque no estaban. Y, de otro lado, que tampoco cabría una exclusión del convenio sin una justificación objetiva y razonable, puesto que ello sería discriminatorio. La naturaleza de su relación con aquella, que no deja de ser laboral, no puede constituir un elemento de exclusión por sí mismo.

En cualquier caso, la solución que se adopte parte de un presupuesto previo: reconocer la subrogación en los supuestos de reversión.

\subsection{La solución a partir de la STC 122/2018, de 31 de octubre de 2018}

Todo este escenario cambia de un modo definitivo con este fallo del TC. De manera simple y directa podemos afirmar que en las leyes de presupuestos únicamente se pueden incluir medidas que afecten al 
gasto público o que estén relacionadas, distinguiendo, en tal sentido, entre contenido esencial y eventual. Ni la DA 26. ${ }^{a}$ ni la DA $34 .^{a}$ se corresponde con aquellos contenidos y por tanto cabe plantearse las siguientes cuestiones:

a) ¿pueden otra vez la Administración Pública, al margen de una resolución judicial, atribuir la condición de Indefinidos no fijos? (v. gr. SAN 10/2/2016).

b) En los procesos de reversión, con la aplicación del art. 44 ET, los trabajadores revertidos adquieren la condición de empleados públicos y, por ejemplo, de indefinidos no fijos ¿o al establecerse otra vez lo mismo en la LPGE (DA 43. ${ }^{a}$ ) estamos en las mismas condiciones que antes de la sentencia?

Sea como sea, y ante la posible nueva consideración por el TC del carácter inconstitucional de la DA 43. ${ }^{a}$ LPGE, no existe impedimento alguno para reconocer la aplicación del convenio colectivo anterior a la reversión por efecto directo de lo previsto en el art. 130 LCSP.

\subsection{Síntesis final}

Veamos, en este sentido y para finalizar los tres escenarios posibles según se ha reconocido anteriormente: sucesión del art. 44 ET si se cumplen los parámetros de tal precepto, subrogación convencional o por vía del pliego de condiciones (vid. de manera amplia: López Cumbre, L., 2018). Dependiendo del cauce, la solución respecto al convenio colectivo aplicable podría ser distinta.

a) Subrogación cauce art. 44 ET: opera la regla allí contenida, los trabajadores se subrogan y el convenio colectivo es que los trabajadores disfrutaban ( $\mathrm{y}$ que la Administración no ha negociado), pero sometido a los condicionantes, plazos, posibles acuerdos sustitutorios, etc. contemplados en el apartado 4 de dicho precepto. Misma solución para la sucesión de plantillas. Y es que dentro del efecto principal de la transmisión de empresa, que no es otro que la subrogación del cesionario en los derechos y obligaciones del cedente, se incluye la regulación de las condiciones de trabajo por convenio colectivo. Aquel que se viniera aplicando a los trabajadores de la empresa cedente (salvo a los trabajadores nuevos: STS 15 de abril de 2014 [RJ 2014, 2945] y art. 3.3 de la Directiva 2001/23/ CE): «salvo pacto en contrario, establecido una vez consumada la sucesión mediante acuerdo de empresa entre el cesionario y los representantes de los trabajadores, las relaciones laborales de los trabajadores afectados por la sucesión seguirán rigiéndose por el convenio colectivo que en el momento de la transmisión fuere de aplicación en la empresa, centro de trabajo o unidad productiva autónoma transferida. Esta aplicación se mantendrá hasta la fecha de expiración del convenio colectivo de origen o hasta la entrada en vigor de otro convenio colectivo nuevo que resulte aplicable a la entidad económica transmitida» (art. 44.4 ET).

b) Subrogación convencional. Varias posibilidades: la primera que se reconozca sucesión de plantillas, en cuyo caso se aplica lo visto en el párrafo precedente. La segunda, que se determinen unos efectos concretos en el convenio colectivo, y a ellos habrá que estar, no pudiendo invocarse que no se ha sido parte en el proceso negociador, puesto que la aplicación de aquel se deriva de un imperativo legal. La tercera, que no se establezcan las consecuencias o alcance de la subrogación convencional: caben, a su vez, dos posibles interpretaciones: o que debería aplicarse, de manera supletoria, el art. $44 \mathrm{ET}$ o, en su caso, que al no tratarse de uno de los supuestos de tal precepto, sí operaría la subrogación, pero directamente respecto a las condiciones establecidas en el convenio del nuevo empleador ya que no se ha establecido ni un procedimiento de transición ni un régimen particular.

c) Pliego de condiciones. Habrá que estar a su contenido concreto y las posibles vías interpretativas que hemos sugerido en el apartado b).

Con ello, no obstante, no se acaban los problemas de interpretación y aplicación. El primero de ellos, recuérdese, el derivado del hecho de que no eran considerado empleados públicos. Sin embargo, entendemos que no por ello pierden su condición de trabajadores que prestan servicios para una Administración, por lo que se integrarían en el ámbito de su convenio salvo que se excluyan de manera objetiva y no discriminaría. Y, en cualquier caso, se ha eliminado dicho problema desde la STC de 31 de octubre de 2018.

Sucedería, en todo caso, cuando se aplique el convenio de la entidad pública, puesto que si se mantiene el anterior de conformidad con el art. $44.4 \mathrm{ET}$, lo que se produciría sería un supuesto especial de concurrencia con una regla especial de articulación que, no obstante, plantearía problemas de duplicidad de convenios para la gestión de personal. Excepto que haya pacto en contrario y considerando que «el art. 44 ET no obli- 
ga al nuevo empresario al mantenimiento indefinido de las condiciones de trabajo previstas en el convenio colectivo que la empresa transmitente aplicaba, lo que impediría la regulación homogénea o unitaria de las condiciones de trabajo, sino sólo a respetar las existentes en el momento de la transferencia, por lo que en el futuro habrá de acomodarse a las normas legales o pactadas que regulan la relación laboral con el nuevo empleador. Tal interpretación no se opone a lo dispuesto en la Directiva 2001/23/CE, puesto que ésta limita la obligatoriedad del cesionario de mantener las condiciones de trabajo pactadas en convenio colectivo hasta la entrada en vigor o aplicación de otro convenio colectivo» (STS 20 de enero de 1997 [RJ 1997/618], STJUE 11-9-2014 [TJCE 2014/220]).

A pesar de todo ello, todavía existen opiniones en el sentido de limitar la subrogación a empresas del mismo sector, estableciendo en caso contrario la imposibilidad de reconocer la misma. Sin embargo, ni el art. 44 ET ni el 130.3 LCSP, limitan en este sentido, por lo que, como conclusión, podemos afirmar que la subrogación convencional tiene plena validez en todo supuesto de reversión como consecuencia de la introducción de una novedosa regla que así lo prevé desde el año 2017, quedando superada, por tanto, las interpretaciones al amparo de una jurisprudencia dictada conforme a la regulación anterior y para supuestos concretos de sucesión de contratas.

Ello claro, salvo mejor parecer...

\section{BIBLIOGRAFÍA}

AA.VV (MONEREO PÉREZ, J. L. [dir.] y VILA TIERNO, F. [coord.]) (2018): Curso de Derecho del Empleo Público. Madrid: Tecnos.

AA.VV (ALFONSO MELLADO, C. A. [coord.]) (2016): Los convenios de empresa de nueva creación tras la reforma laboral de 2012. Elaborado por el Observatorio para la negociación colectiva. Madrid: CC.OO / Lefevre el Derecho.

ALFONSO MELLADO, C. (2016): "La reversión a la gestión directiva de servicios públicos. Problemas laborales", en Revista de derecho social, núm. 73, págs. 25-44.

AMAADACHOU KADDUR, F. (2015): "La determinación de las partes que conciertan el convenio colectivo de naturaleza estatutaria", en Nueva revista española de derecho del trabajo, núm. 180, págs. 267-304.

CASTILLO BLANCO, F. (2017): "La reinternalización de servicios públicos: aspectos administrativos y laborales", en Estudios de Relaciones Laborales. Barcelona: CEMICAL.

CRUZ VILLALÓN, J. (2016): "Claves laborales de la participación privada en la actuación pública", en Temas Laborales, núm. 135.

GARCÍA-PERROTE ESCARTíN, I. y MERCADER UGUINA, J. R. (2014): "EI principio de correspondencia representativa como límite en la negociación de empresa", en Revista de información laboral, núm. 3.

GÓMEZ ÁLVAREZ, T. (2004): La transformación de las Administraciones Públicas. Madrid: CES.

GORELLI HERNÁNDEZ, J. (2018): "Las condiciones laborales de los trabajadores de los servicios públicos objeto de reversión", en Curso de verano de la Universidad de Málaga (Marbella; 3 a 6 de julio de 2018) sobre "La externalización y remunicipalización de los servicios públicos".

LÓPEZ CUMBRE, L. (2017): "Limitaciones a la incorporación de personal laboral en el sector público. Reglas de subrogación y empleo público", en Revista Galega de Dereito Social - 2. ${ }^{2}$ etapa: (RGDS), núm. 3, págs. 101-147.

MOLINA NAVARRETE, C. (2017): Indemnización por cese en el empleo público, crónicas y críticas de su actividad judicial. Albacete: Bomarzo.

MONEREO PÉREZ, J. L. (2016): "Repercusiones laborales de los diversos instrumentos de privatización y reversión de servicios públicos", en Temas laborales. Revista andaluza de trabajo y bienestar social, núm 135, págs. 251307.

SALA FRANCO, T. (2018): "Acceso de los derechos de los trabajadores en los casos de reversión en la gestión de servicios públicos por las Administraciones públicas", en Derecho de las Relaciones Laborales, núm. 2.

SÁNCHEZ MORÓN, M. (dir.) (2007): Comentarios a la Ley del Estatuto del Empleado Público. Madrid: Lex Nova.

TOMÁS JIMÉNEZ, N. (2013): Los sujetos del convenio colectivo. Partes negociadoras. Granada: Comares.

VILA TIERNO, F. (2018): Problemática en materia de contratación laboral en la Administración Pública Local. Algunas cuestiones de actualidad. Granada: Comares.

VILA TIERNO, F. (2008): Guía Breve para la Búsqueda del convenio colectivo aplicable. Legal Today: http://www. legaltoday.com/practica-juridica/social-laboral/laboral/guia-practica-breve-para-la-busqueda-del-conveniocolectivo-aplicable\#. 